\title{
(2) OPEN ACCESS \\ Recurrent ventricular tachycardia associated with lipomatous metaplasia of a myocardial scar
}

\author{
Amer Hussein Muhyieddeen 다, ${ }^{1}$ Miro Asadourian, ${ }^{1}$ Siri Kunchakarra, ${ }^{2}$ Ankit Rathod ${ }^{2}$
}

${ }^{1}$ Internal Medicine, UCSF Fresno Center for Medical Education and Research Edward and Ann Hildebrand Medical Library, Fresno, California, USA ${ }^{2}$ Cardiology, UCSF Fresno Center for Medical Education and Research Edward and Ann Hildebrand Medical Library, Fresno, California, USA

Correspondence to Dr Amer Hussein Muhyieddeen; amuhyieddeen@fresno.ucsf.edu

Accepted 3 March 2021

Check for updates

(c) BMJ Publishing Group Limited 2021. Re-use permitted under CC BY-NC. No commercial re-use. See rights and permissions. Published by BMJ.

To cite: Muhyieddeen $\mathrm{AH}$, Asadourian $\mathrm{M}$

Kunchakarra S, et al. BM」

Case Rep 2021:14:e240626.

doi:10.1136/bcr-2020-

240626

\section{SUMMARY}

Lipomatous metaplasia in chronic postmyocardial infarction scars is a common and underappreciated finding seen in histopathology and cardiac MRI. Evidence suggests that lipomatous metaplasia is capable of altering the electroconductivity of the myocardium leading to re-entry pathways that are implicated in the pathogenesis of postmyocardial infarction arrhythmogenesis. We report a case of a patient who presented with non-sustained ventricular tachycardia and was found to have lipomatous metaplasia of a prior myocardial infarct-related scar.

\section{BACKGROUND}

Adipose tissue within the myocardium has been shown to alter heart electroconductivity, leading to an increased predisposition for arrhythmias and sudden cardiac death. ${ }^{1}$ Initially noted on pathological specimens, adipose infiltration into the myocardium was termed lipomatous metaplasia by Baroldi and colleagues. ${ }^{1}$ The significance of lipomatous metaplasia is currently unclear; however, it is known to be the pathological culprit in arrhythmogenic right ventricular cardiomyopathy. ${ }^{2}$ Its presence has also been associated with more adverse cardiac remodelling and larger infarct size. ${ }^{3}$ More recently, studies involving cardiac MRI (CMR) have been able to non-invasively characterise the presence of lipomatous metaplasia. ${ }^{4}$ CMR allows excellent image resolution and is regarded as the gold standard for assessing cardiac morphology and function. CMR has an added benefit in that it can visualise a myocardial scar with a high degree of precision. ${ }^{5}$ By using a combination of fat-water separation and conventional delayed enhancement imaging, it is possible to accurately assess the adiposity of chronic myocardial infarction scars. Using these image processing methods, some observational CMR studies have reported the prevalence of lipomatous metaplasia in patients with healed myocardial infarction scars to be as high as $78 \%$. $^{6}$

\section{CASE PRESENTATION}

A 77-year-old man with recurring colon cancer was admitted for a scheduled left hemi-colectomy. On postoperative day 3, the patient began to experience isolated runs of non-sustained ventricular tachycardia (VT) (figure 1). Throughout these VT episodes, the patient was asymptomatic, and presented with no chest pain or shortness of breath. Inpatient cardiology was consulted to evaluate the patient. On physical examination, vital signs were stable. The patient had no signs of elevated jugular vein distension, cyanosis, peripheral oedema or abnormal heart sounds, and his lungs were clear to auscultation bilaterally.

\section{INVESTIGATIONS}

Labs were normal with no indications of anaemia, electrolyte derangements or metabolic abnormalities. An ECG showed normal sinus rhythm with premature ventricular contractions and $\mathrm{Q}$ waves in the inferior leads. A transthoracic echocardiogram revealed an ejection fraction of $65 \%$ with no significant wall motion abnormality. The patient was discharged with beta-blocker therapy and outpatient cardiology follow-up. He was monitored for 2 weeks with an ambulatory cardiac monitor, which showed several runs of non-sustained VT. Coronary angiography showed moderate stenosis of the right coronary artery with normal fractional flow reserve and no other areas of haemodynamically significant stenosis. As the echocardiogram showed no evidence of structural abnormalities, CMR was done to evaluate structural abnormalities. CMR revealed a crescent-shaped mass in the basal inferoseptal wall of the left ventricle. The mass measured approximately $4 \mathrm{~mm}$ in thickness and $2 \mathrm{~cm}$ in length. It appeared to have a central area of hyperintensity surrounded by a rim of hypointense signal relative to the myocardium when visualised with steady-state free precession (SSFP) sequences (figure 2). The mass was mostly subendocardial in the majority of the inferoseptal wall, but within the basal-inferior wall, it appeared to be mid-myocardial. When imaged with double inversion recovery $\mathrm{T} 2$ imaging, the mass appeared to have a slight hyperintensity in its signal. However, fat suppression on double and triple inversion recovery imaging adequately suppressed the signal, suggesting fatty tissue (figure 3). Furthermore, perfusion imaging showed that the subendocardial portion of the inferior wall and inferoseptum had mild perfusion abnormalities. Late gadolinium enhancement images showed subendocardial scarring in the basal inferior and inferoseptal wall along with mid-myocardial extension corresponding to SSFP images (figure 4). This was due to the metaplastic tissue extending into the mid-myocardial tissue of the basal inferior wall. This led to an abnormal crescent appearance that is not typical for a simple infarct-related scar. Given the overall context of the scar tissue and its appearance as a mid-myocardial mass, it was determined to be a lipomatous metaplasia of a prior myocardial infarction-related scar.

\section{DIFFERENTIAL DIAGNOSIS}

Given the asymptomatic presentation and telemetry findings, the differential diagnosis included 


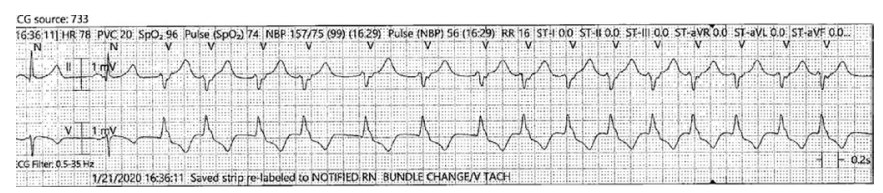

Figure 1 Isolated runs of non-sustained ventricular tachycardia.

supra-VT with aberrancy due to bundle branch block versus VT due to metabolic derangements versus VT due to ischaemia.

\section{TREATMENT}

Given that the patient was asymptomatic throughout all episodes of VT and had no symptoms or signs of heart failure or cardiovascular compromise, the patient has to be continued on betablocker therapy.

\section{OUTCOME AND FOLLOW-UP}

The patient was scheduled to be seen by a cardiac electrophysiologist on completion of his chemotherapy. He underwent an electrophysiological study which failed to induce VT. The patient remained asymptomatic with no signs of heart failure and was continued on beta-blocker therapy in the interim.

\section{DISCUSSION}

Ischaemia typically presents on CMR as scarring that mainly involves the subendocardium. ${ }^{7}$ With progression on the size of the infarct, the scar may spread to the epicardium in a manner consistent with the 'wavefront phenomenon' of ischaemic cell death. ${ }^{8}$ In our patient, the appearance of the scar was unusual given its isolated mid-myocardial appearance. Myocardial adiposity has been shown to increase the susceptibility for VT. Adipose tissue plays a major role in altering the electrophysiological mechanisms of the myocardium than does collagen. In an animal model involving sheep with experimentally induced myocardial infarction, collagen was not found to significantly induce VT. In contrast, increased lipomatous metaplasia was significantly associated with critical re-entrant circuits leading to $\mathrm{VT}^{9}{ }^{\text {Fat }}$ deposition also has prognostic significance. In a prospective study involving 316 patients with prior myocardial infarction, lipomatous metaplasia was a significant predictor of all-cause mortality, sustained VT and hospitalisation for heart failure. $^{3}$ Furthermore, a multivariable analysis including other strong predictors (atrial fibrillation, reduced left ventricular ejection fraction (LVEF), diabetes and multivessel disease) found that lipomatous metaplasia remained a significant predictor of allcause mortality, more adverse remodelling and larger infarcts. ${ }^{3}$

Current guidelines recommend echocardiography as the firstline tool for patients presenting with heart failure or VT. CMR becomes a class 1 recommendation when an infiltrative cause is

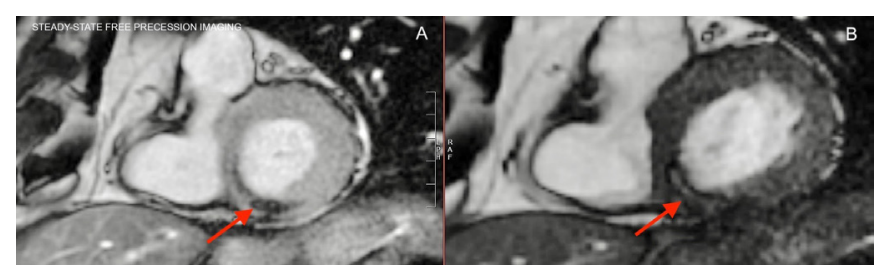

Figure 2 Steady-state free precession (SSFP) MRI: image (A) on the left involves SSFP pre-contrast, while image (B) on the right shows SSFP post-contrast with notable intake in the mid-myocardium. The arrows in the figure point to the crescent-shaped mass in the basal inferoseptal wall of the left ventricle.

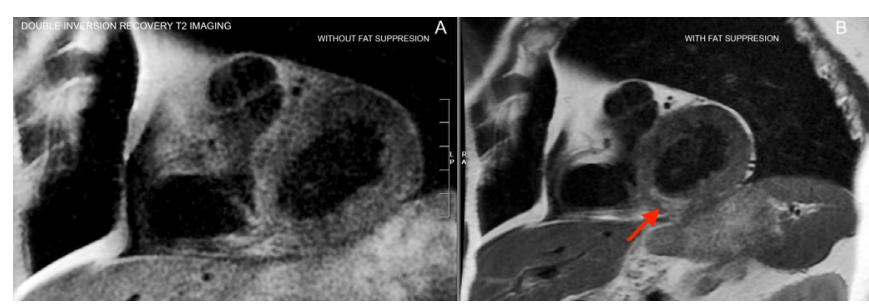

Figure 3 Double inversion recovery sequence on T2 imaging: image (A) on the left shows without fat suppression, while image (B) on the right shows with fat suppression. The red arrow in the figure points to the crescent-shaped mass of lipoid tissue in mid-myocardium.

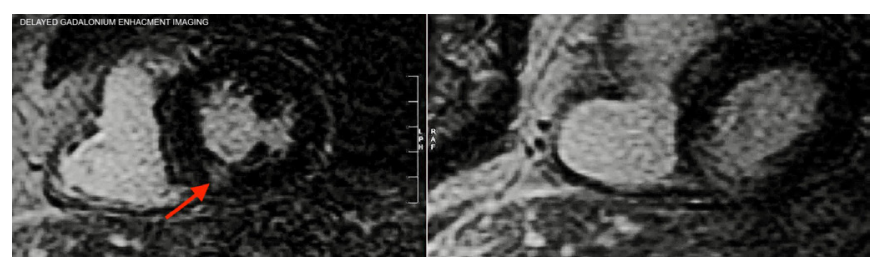

Figure 4 Delayed gadolinium enhancement images. The arrow points to the subendocardial scar showing delayed gadolinium enhancement.

suspected. ${ }^{10}$ However, CMR is better at characterising LVEF and myocardial mass due to its reproducibility and accuracy. CMR can also overcome the inadequate echocardiographic acoustic windows and identify the aetiology of ischaemic and nonischaemic cardiomyopathies. ${ }^{10}$ CMR's usefulness in evaluating patients with VT is highlighted by studies showing improvement of up to $50 \%$ in identifying relevant myocardial disease compared with routine non-CMR-based imaging. ${ }^{11}$ Additionally, CMR characterised cardiac disease as significant in a quarter of patients classified as having normal structure and function using non-CMR imaging. ${ }^{11}$

It is important to identify lipomatous metaplasia in patients with deadly arrhythmias who plan to have ablative procedures. In a recent study involving a group of 72 patients undergoing ablation for VT, fat deposition within the myocardium was associated with worse outcomes and higher rates of VT recurrence. ${ }^{12}$ Further strategies must be implemented before proceeding with invasive procedures in this patient population. Future implications may suggest broader and earlier use of CMR to evaluate the presence of lipomatous metaplasia in post-myocardial infarction scars and better risk stratification of patients prior to ablation to predict propensity for VT and mortality.

\section{Learning points}

- Lipomatous metaplasia is a common and underappreciated finding in postmyocardial infarction scars.

- Intramyocardial adipose tissue is a significant risk factor in the induction of postmyocardial infarction ventricular tachycardia.

- Cardiac MRI is an excellent imaging modality due to its high reliability in tissue characterisation, left ventricular function, viability assessment and lack of radiation exposure.

Contributors AHM and MA were responsible for writing and drafting the manuscript. SK and AR were responsible for reviewing, guiding and editing the final draft. Responsible for interpreting cardiac MRI images.

Funding The authors have not declared a specific grant for this research from any funding agency in the public, commercial or not-for-profit sectors. 
Competing interests None declared.

Patient consent for publication Obtained.

Provenance and peer review Not commissioned; externally peer reviewed.

Open access This is an open access article distributed in accordance with the Creative Commons Attribution Non Commercial (CC BY-NC 4.0) license, which permits others to distribute, remix, adapt, build upon this work non-commercially, and license their derivative works on different terms, provided the original work is properly cited and the use is non-commercial. See: http://creativecommons.org/ licenses/by-nc/4.0/.

ORCID iD

Amer Hussein Muhyieddeen http://orcid.org/0000-0003-1179-1103

\section{REFERENCES}

1 Baroldi G, Silver MD, De Maria R, et al. Lipomatous metaplasia in left ventricular scar. Can J Cardiol 1997;13:65-71.

2 Corrado D, Link MS, Calkins H. Arrhythmogenic right ventricular cardiomyopathy. N Engl J Med 2017:376:61-72.

3 Mordi I, Radjenovic A, Stanton T, et al. Prevalence and prognostic significance of lipomatous metaplasia in patients with prior myocardial infarction. JACC CardiovasC Imaging 2015;8:1111-2

4 Deux J-F, Rahmouni A, Garot J. Cardiac magnetic resonance and 64-slice cardiac CT of lipomatous metaplasia of chronic myocardial infarction. Eur Heart J 2008;29:570.
5 Mahida S, Sacher F, Dubois R, et al. Cardiac imaging in patients with ventricular tachycardia. Circulation 2017;136:2491-507.

6 Goldfarb JW, Roth M, Han J. Myocardial fat deposition after left ventricular myocardial infarction: assessment by using Mr water-fat separation imaging. Radiology 2009;253:65-73

7 Senthilkumar A, Majmudar MD, Shenoy C, et al. Identifying the etiology: a systematic approach using delayed-enhancement cardiovascular magnetic resonance. Heart Fail Clin 2009:5:349-67.

8 Reimer KA, Lowe JE, Rasmussen MM, et al. The wavefront phenomenon of ischemic cell death. 1. myocardial infarct size vs duration of coronary occlusion in dogs. Circulation 1977;56:786-94.

9 Pouliopoulos J, Chik WWB, Kanthan A, et al. Intramyocardial adiposity after myocardial infarction: new implications of a substrate for ventricular tachycardia. Circulation 2013;128:2296-308.

10 Ponikowski P, Voors AA, Anker SD, et al. 2016 ESC Guidelines for the diagnosis and treatment of acute and chronic heart failure: The Task Force for the diagnosis and treatment of acute and chronic heart failure of the European Society of Cardiology (ESC)Developed with the special contribution of the Heart Failure Association (HFA) of the ESC. Eur Heart J 2016;14;37:2129-200.

11 White JA, Fine NM, Gula L, et al. Utility of cardiovascular magnetic resonance in identifying substrate for malignant ventricular arrhythmias. Circulation 2012:5:12-20.

12 Ghassen C, Soumaya S, Frederic S, et al. Post-Myocardial infarction scar with fat deposition shows specific electrophysiological properties and worse outcome after ventricular tachycardia ablation. J Am Heart Assoc 2019;8:e012482.

Copyright 2021 BMJ Publishing Group. All rights reserved. For permission to reuse any of this content visit

https://www.bmj.com/company/products-services/rights-and-licensing/permissions/

BMJ Case Report Fellows may re-use this article for personal use and teaching without any further permission.

Become a Fellow of BMJ Case Reports today and you can:

- Submit as many cases as you like

Enjoy fast sympathetic peer review and rapid publication of accepted articles

- Access all the published articles

Re-use any of the published material for personal use and teaching without further permission

Customer Service

If you have any further queries about your subscription, please contact our customer services team on +44 (0) 2071111105 or via email at support@bmj.com.

Visit casereports.bmj.com for more articles like this and to become a Fellow 